\title{
A Comparison Research on Industry-University-Research Strategic Alliances in Countries
}

\author{
Chunhua Feng, Mengchun Ding \& Baojun Sun \\ School of Economics \& Management, Changchun University of Science \& Technology \\ Changchun 130022, China \\ E-mail: fengchunhua918@sina.com
}

\begin{abstract}
With the tide of global economic integration, the Industry-University-Research cooperation plays an extremely important role in economic development. Hence, all countries in the world stress the research on Industry-University-Research strategic alliance. Some developed countries, such as America, German, and England, have built appropriate modes for Industry-University-Research strategic alliances based on national conditions. The strategic alliance based on combination of different countries, enterprises, and institutes has been becoming a new way for technology transfer.
\end{abstract}

Keywords: Industry-university-research, Strategic alliance, Comparison research

The $21^{\text {st }}$ century is the times of knowledge-based economy. All countries are challenged by economic informatization, globalization, and network. They all realize that the industry competitiveness is the core of a country's international competitiveness. The Industry-University-Research strategic alliance is an interaction between universities, scientific institutes, and enterprises.

\section{The meaning of Industry-University-Research strategic alliance}

\subsection{Strategic alliance}

Two or more powerful enterprises or special cause and functional departments form a loose network organization mode by contracts in order to achieve common strategic goals.

\subsection{Concept of Industry-University-Research strategic alliance}

The Industry-University-Research strategic alliance is a brand-new cooperation mode, in which enterprises are the subjects, and the "technology-information-knowledge" exchange the main way. All parties in the cooperation remain a stable, long-term, co-existent, and mutually-beneficial relationship. It is an important component in national innovative system.

\subsection{The relationship of Industry-University-Research cooperation and Industry-University-Research strategic alliance}

Industry-University-Research strategic alliance is the advanced form of Industry-University-Research cooperation, as the product from the development of Industry-University-Research cooperation. There are sharp differences between Industry-University-Research strategic alliance and common Industry- University-Research cooperation. It main characteristics are:

(1) The relationship of members in Industry-University-Research strategic alliance is long-term: the cooperation in Industry-University-Research strategic alliance is not a temporary cooperation but a relatively stable and long-term cooperation. In strategy, they hope to achieve long-term benefits by cooperation, strengthening the competitive advantages.

(2) Activities of Industry-University-Research strategic alliance focus on the strategy. The alliance is a kind of cooperation of universities, enterprises, and scientific research institutes from a point view of strategy. It is a strategic measure adopted by all cooperative parties for the sake of self benefits. By means of strategic alliance, all parties can collect resources and advantages in all aspects. Enterprises can decrease the R\&D costs and improve competitiveness. Universities and scientific research institutes can achieve the strategic success in talent training mechanism and scientific research development.

(3) The overall interests of all members in Industry-University-Research strategic alliance are complementary. The strategic alliance reflects an interest-complementary relationship of cooperative members, instead of a 
common market trading or assistant relationship. The strategic alliance reaches the synergistic effect on each member, avoiding disadvantages and benefiting from advantages mutually. For example, by means of strategic alliance, universities can drive the development of disciplines and enterprises can improve the competitiveness.

\section{The Industry-University-Research strategic alliance in Silicon Valley}

Silicon Valley is the most important electronics industry base in America, and also the most famous electronics industry center in the world. At the $60 \mathrm{~s}$ in $20^{\text {th }}$ century, microelectronic technology develops fast. Based on some world famous universities, such as Stanford, Caltech, and Berkeley, the high-tech technological industry zone appears, in which the science, production, and technology combine together. Today, Silicon Valley produces one sixth of computers and one third of semiconductor integrated circuits in America. Now as we mention Silicon Valley, everybody knows that it is the place for semiconductor industry in countries of the world.

\subsection{In the development of Silicon Valley, Stanford offers the policy of Industry-University-Research cooperation}

(1) Provide beneficial policies for teachers' scientific research. Stanford encourages teachers to join in scientific research and development. It maintains a long-term close cooperation with Silicon Valley. Stanford transfers the research fruits to high-tech enterprises and supplies numerous innovative talents for Silicon Valley. In Stanford, teachers are the chief roles. The university means to improve teachers' ability of scientific research. The standard for assessing the Industry-University-Research cooperation is the transfer ratio of scientific research.

(2) Build research centers and implement the "honorary co-operation project"

The vice president of Stanford founded an honor cooperation program in 1954. Enterprises can send employees to receive higher education in universities, which can help enterprises in cooperation to maintain competitive advantages. Stanford University established amounts of research centers, by which the connection between Stanford and Silicon Valley was strengthened. Universities can apply the latest researches to enterprises.

\subsection{Venture capital plays an important role in the development of Silicon Valley}

Silicon Valley has independent financial system. Some large enterprises can make reinvestment by own wealth, inputting venture capitals in high-tech small and medium-sized enterprises. Venture capital offers funds for the transformation of scientific and technological achievements, solving the capital problem for high advanced technologies. Meanwhile, venture capital firms can provide value-added services for small and medium-sized enterprises. For instance, they can help small and medium-sized enterprises to explore market and improve management with their knowledge and experiences.

\section{The Industry-University-Research strategic alliance in German}

\subsection{The Center of Knowledge Interchange (CKI) mode}

In German, Siemens seek for cooperation with leading universities eagerly and set up Centers of Knowledge Interchange (CKI), such as the Center of Knowledge Interchange established by Siemens and Rheinisch-Westfaelische Technische Hochschule (RWTH) Aachen University, and the Center of Knowledge Interchange established by Siemens and Technical University of Munich. Centers of Knowledge Interchange (CKI) are actually the strategic alliance of Siemens and universities. CKI specifically focuses on innovation management, personnel training, personnel network, and scientific and technological human resource management.

\subsection{The characteristics of Germany Industry-University-Research strategic alliance}

The Center of Knowledge Interchange is long-term strategic cooperation but not short-term alliance. It is based on strengths of universities and makes interdisciplinary researches. It centers on one knowledge field and develops several programs at the same time, driving the mutual transformation between capitals and knowledge.

\subsection{The strategic alliance takes market as the core}

Enterprises present cooperation program for allied universities according to market demand and offer all capitals. Universities are responsible for research and development. Then enterprises test the achievements and push products into the market together with universities.

\section{The Government-Industry-University strategic alliance in Korea}

Korea, as a new developed country, has a scientific and technological innovation system including government, universities, research institutes, and enterprises. The government creates the favorable environment for innovation, make up relevant policies and regulations, and encourage innovative activities in Industry-University-Research cooperation. 


\subsection{The government gives policy support and legislative guarantee for Industry-University-Research cooperation}

In Korea, it is the government that establishes the major scientific research projects. The government advocates and supervises the Industry-University-Research cooperation and makes up a series of laws and beneficial policies: (1) supply sufficient capitals for Industry-University-Research cooperation; (2) apply the tax exemption and reduction policy for cooperative researches, mainly focus on enterprises' research centers in scientific and technological zone; (3) implement the priority loan policy, mainly for technological development rewards, venture capital, and industrial technology development fees; (4) provide technological help for small and medium-sized enterprises and set up industry technology development center; (5) sell government-supported R\&D fruits at lower price and drive the transformation of scientific and technological achievements; (6) supply computer network services.

\subsection{The Government-Industry-University strategic alliance}

The Government-Industry-University strategic alliance is the main way for technological innovation in Korea. It is good at making best use of advantages of alliance members. The main forms are:

(1) The Government-Industry-University common research unity that takes up national R\&D programs. In this mode, the government supplies funds and makes public bidding. The aim is to drive the cooperation between members.

(2) Build up various industrial technological research combinations between enterprises, and enterprises and universities (scientific research institutes).

(3) Enterprises entrust universities and scientific research institutes to perform $R \& D$, establishing the development targets and interests distribution by contracts.

(4) Build research zones centering on universities, expertise the transformation of R\&D achievements to enterprises, promote the cooperation of all parties in the Industry-University-Research alliance, and make best use of resources and advantages of all parties.

(5) Cooperate with foreign universities and research institutes. Get the latest scientific and technological information by foreign advanced equipments and personnel resources.

\section{Experiences and enlightenments from other countries' Industry-University-Research strategic alliance}

5.1 The Industry-University-Research strategic alliance should rely more on government's management and direction

In the Industry-University-Research alliance, it is necessary to emphasize the effect of government, stimulate members' enthusiasm, build a government-dominated national innovation system, offering institutional guaranty for allied enterprises' independent innovation and development. To build regional scientific and technological innovation system, we must emphasize more on government's management and direction. All local governments should make up a series of beneficial policies driving the Industry-University-Research cooperation, according to local economic development and social needs, providing better environment and conditions for regional innovation.

\subsection{The Industry-University-Research strategic alliance should build and improve the intermediary service agencies}

Intermediary service agencies are indispensable supportive powers in Industry-University-Research strategic alliance. In the alliance, intermediary service agencies can help enterprises to find suitable universities or scientific research institutes on one hand. On the other hand, they help universities to understand the needs of enterprises, which make the later to readjust the research orientation. As universities or scientific research institutes and enterprises develop strategic alliance, they have to rely on intermediary service agencies by legal contracts. By means of these intermediary service agencies, universities or scientific research institutes develop cooperative research with enterprises. Therefore, we must build and improve various intermediary service agencies, which would supervise the fulfillment of agreements or contracts during the transformation process. Improve the service functions of intermediary service agencies. Make sure that intermediary service agencies are capable of being consultants and offering guaranties.

\subsection{The Industry-University-Research strategic alliance should completely pay attention to the subjective status completely}

English government extremely values small and medium-sized enterprises. In order to help them acquire more innovation sources, the government takes some measures in fields of finance and tax to promote the cooperation 
of small and medium-sized enterprises and research institutes and universities. The government builds the small and medium-sized enterprises service bureau and other scientific and technological intermediary service agencies. To support the development of small and medium-sized enterprises is an important ring for national innovation strategy. In building the technological innovation system, we must deal with the relationship between enterprises and Industry-University- Research alliance properly. The Industry-University-Research alliance is an important component of technological innovation system.

5.4 The Industry-University-Research strategic alliance should attach importance to talent training and cultivation of innovative spirits

All Industry-University-Research strategic alliances, mentioned above, focus on the training of talents. Talents are the base for the development of enterprises and universities. By means of Industry- University-Research strategic alliance, students can explore their innovative spirits and professional knowledge. On the other hand, the alliance can deepen college students' understandings to alliance member enterprises. Then, the later can attract more excellent college students. The Industry- University-Research strategic alliance is a kind of education mode. The Industry-University-Research strategic alliance must value the "people-oriented" educational thought. It needs the complete involvement of college students, who can receive overall education and training in Industry- University-Research strategic alliance. It is meaningful for improving the general quality of college students. By this way, it offers more spaces and guaranties for college students' overall development.

5.5 The Industry-University-Research strategic alliance should build up a perfect scientific and technological information service system

Information is determinative for the success of technological innovation. The Industry-University- Research strategic alliance needs a set of complete and systematic scientific and technological information net, relatively collecting the authorities in information service industry, and ensuring the smooth flow of scientific and technological information. Building a scientific and technological information system can allocate and distribute all resources reasonably in the industry, avoiding wastes, improving efficiency, satisfying the deeper needs of enterprises, and make full use of scientific and technological achievements.

\subsection{The Industry-University-Research strategic alliance should make wide financing}

Sufficient investments are important guaranty for promoting the development of Industry-University- Research strategic alliance. We should take multi-faceted, multi-level, and multi-channel financing channels to drive the Industry-University-Research strategic alliance. In this aspect, the government should play its role in financing for cooperation. First of all, the government should increase the direct investments by means of different forms, and support the development of Industry-University-Research strategic alliance, improving enterprises' competitiveness and overall national strength. Secondly, encourage social investments in Industry-University-Research cooperation, build and improve the venture capital mechanism, and increase social focus and investment in scientific research and education. Besides, national authorities can set up a special loan for Industry-University-Research strategic alliance, and lay specific stress on high-tech projects with a prospect of industrialization, supplying necessary funds on one hand, and on the other hand constituting an appropriate supervision mechanism.

\section{References}

Li, Bo. (2004). Industry-University-Research cooperation in Japanese universities and enlightenments. Journal of Hexi University, No. 4.

Liu, Li. (2006). American Industry-University-Research cooperative mode and successful experiences. Education Development Research, No. 4.

Liu, Lifang. (2009). Successful experiences of foreign Industry-University-Research cooperation and enlightenment. Commercial Times, No. 5.

Sun, Fuquan. Chen, Baoming \& Wang, Wenyan. (2008). Industry-University-Research cooperation innovation in main developed countries------ basic experiences and inspirations, No. 1.

Wang, Xueyuan \& Wang, Hongqi. (2008). Operation mechanisms and strategy research of produce study and research strategy alliance under the guidance of government. Science \& Technology Progress and Policy, No. 6.

Zhu, Dongwei. (2006). Research on the typical mode for Industry-University-Research cooperation and enlightenment. Science \& Technology Industry of China, No. 12.

Zhu, Jun. Chen, Jinqing \& Peng, Zhiyong. Et al. (2007). The road of innovative country: the ally of industry, college, and research department. Science and Technology Management Research, No. 5. 